\title{
Comparing the provision of ecosystem services in plantation forests under alternative climate change adaptation management options in Wales
}

\author{
Duncan Ray $\cdot$ Stephen Bathgate $\cdot$ Darren Moseley $\cdot$ \\ Philip Taylor $\cdot$ Bruce Nicoll $\cdot$ Stefania Pizzirani • \\ Barry Gardiner
}

Received: 28 January 2014 / Accepted: 7 June 2014/Published online: 24 July 2014

(c) The Author(s) 2014. This article is published with open access at Springerlink.com

\begin{abstract}
To compare the provision of ecosystem services in plantation forests under alternative climate change adaptation management trajectories, we interpolated climatic variables from the UK 11-member regional climate models to use at high resolution in forest management situations. We used expert opinion to derive the links between coarse-scaled UK National Ecosystem Assessment scenarios and forest management alternatives (FMA) in a simulation of forest planning and management under climate change uncertainty. Nine indicators were used to compare the provision of forest ecosystem services from four alternative management trajectories based on FMA types under a changing climate. These show that by 2080 a 'business as usual' form of forest management at both Clocaenog and Gwydyr forests will become unsuitable under the two warmest and driest climate variants, marginal under four variants, and borderline suitable under the remaining five variants. This implies that if future forest
\end{abstract}

Electronic supplementary material The online version of this article (doi:10.1007/s10113-014-0644-6) contains supplementary material, which is available to authorized users.

D. Ray $(\bowtie) \cdot$ D. Moseley $\cdot$ P. Taylor

Centre for Ecosystems, Society and Biosecurity, Forest

Research, Roslin, Midlothian EH25 5SY, Scotland, UK

e-mail: duncan.ray@forestry.gsi.gov.uk;

duncan.ray@forestry.gov.uk

D. Moseley

e-mail: darren.moseley@forestry.gsi.gov.uk

P. Taylor

e-mail: philip.taylor@forestry.gsi.gov.uk

S. Bathgate $\cdot$ B. Nicoll

Centre for Sustainable Forestry and Climate Change, Forest

Research, Roslin, Midlothian EH25 5SY, Scotland, UK

e-mail: stephen.bathgate@forestry.gsi.gov.uk policy requires the continued delivery of a wide range of ecosystem services, including, home grown timber, biodiversity, and the carbon mitigation benefit from woodlands, then there is $20-50 \%$ chance of failing to deliver on some of these services, unless some adaptation measures to climatic impacts occurs, such as transformation to more diverse species forests managed using low-impact silviculture systems. We show that the benefits of achieving this will be to minimise most of the impacts that climate change would otherwise have on the delivery of ecosystem services from forests.

Keywords RCM projections - Ecosystem goods and services · UK National Ecosystem Assessment .

Adaptation · FMA · Forest modelling · Forest resilience

\section{Introduction}

Due to the long rotation periods of forest stands, and because of the many benefits people derive from forests (Quine et al. 2011), it has been recognised that climate

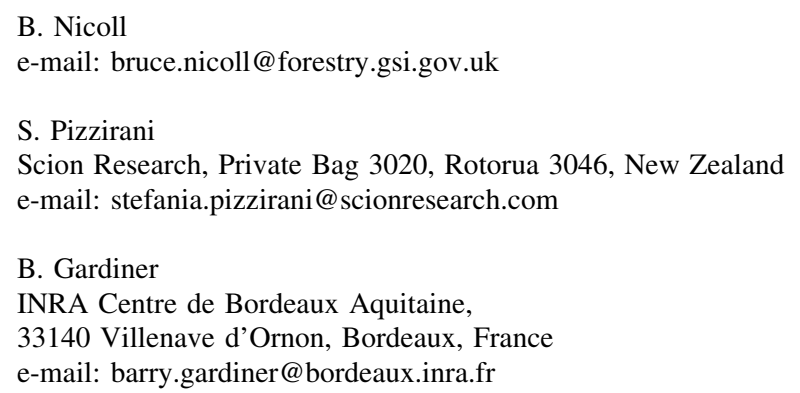


change will have a considerable impact on the provision of ecosystem goods and services from forests (Hurteau et al. 2013; Lindner et al. 2010; Steenberg et al. 2011). Consequently, resilient forest adaptation should be considered, including counter measures (Hanewinkel et al. 2013; Rist and Moen 2013) to maintain the continued long-term delivery of ecosystem goods and services from wooded landscapes (Fürstenau et al. 2007; Rasche et al. 2013; Stein et al. 2013). Climate change adaptation requires adjustments in species or provenance selection and the choice of a suitable silvicultural system to reduce damaging extreme abiotic and biotic impacts (Broadmeadow et al. 2005) to forest ecosystems.

Management to maintain ecosystem function is recognised as a pre-requisite (Benayas et al. 2009) to ecosystem services delivery, and the Millennium Ecosystem Assessment (MEA 2005) and the UK National Ecosystem Assessment (UKNEA 2011) both demonstrate the key role of sustainable management according to the ecosystem approach (MCPFE 2006) to support the delivery of goods and services that benefit people. The UK has adopted policy (Defra 2011) to manage land sustainably and to consider and improve the delivery of goods and services. This policy is also reflected in the devolved countries, which considers spatial and holistic assessments of ecosystem services and climate adaptation, with plans for introducing payments for their delivery.

Climate change uncertainty and the implications for land management decision-making has been widely discussed in the literature (Berkhout et al. 2013; Courbaud et al. 2010; Hurteau et al. 2013; Millar et al. 2007; Petr et al. 2014; Seidl and Lexer 2013; Yousefpour et al. 2012). In the UK, climate change uncertainty is represented by the probabilistic United Kingdom Climate Projections (UKCP 2009). A by-product of the probabilistic projections was the creation of regional climate model (RCM) outputs comprised of 11 equally likely variants from a perturbed physics ensemble and gridded at a resolution of $25 \mathrm{~km}$, to represent a daily climatology for the UK from 1950 to 2100 . These variants have been used to study drought risk (Brown et al. 2011), and they provide a way of exploring the spatial and temporal uncertainty of climate projections in the UK.

The forest land area of the UK has increased from approximately $5 \%$ in the early twentieth century to around $13 \%$ by 2012 . During this time, various social and economic pressures forced changes in policy throughout the twentieth century, with changes and adjustments to the forest ecosystem state leading to responses in ecosystem service delivery. This 'pressure-state-response' framework has been clearly evident during the last century. From an initial need for a strategic timber reserve, an issue of national security (Richards 2003), to a requirement to realise greater forestry employment opportunities (Linnard 2000), and in the 1980s to restructure wooded landscapes to correct biodiversity, cultural and aesthetic losses (Mason 2007) resulting from widespread uniform forest plantations. Recently sustainable forest management objectives have been implemented to deliver a range of goods and services (Quine et al. 2013).

The pressure-state-response framework logic may be carried forward into the future. Indeed one can associate the different socio-economic future scenarios developed in the UK National Ecosystem Assessment (UK NEA) (Haines-Young et al. 2011) with likely forest policy drivers forcing changes in forest planning and forestry practice, which in turn would lead to the implementation of forest management systems to deliver the ecosystem services demanded by forest policy. For example, Haines-Young et al. (2011) calculated that by 2060, the area of woodland in the UK would increase in five of the six storylines, the exception being 'World Markets'. Detail in the spatial variation of ecosystem service provision from woodlands was beyond the scope of the UK NEA (Quine et al. 2011), and consequently there was no detailed treatment of differences in ecosystem service provision among forest management and silvicultural systems. However, this type of assessment is more appropriate at the regional or catchment scale, and such an experiment provides an opportunity to simulate changes in forest management alternatives (FMA) from existing states to future projected states. Such an experiment could simulate a more realistic response to policy drivers and offer a test of future forest resilience (Rist and Moen 2013) from different adaptation strategies using a temporal and spatial simulation of indicators of ecosystem service delivery.

There is a very clear rationale for linking climate change adaptation with ecosystem service delivery from woodland and forest. The simulated assessment of ecosystem goods and services provides evidence to planners of the effect of different trajectories of climate change adaptation management. This can reveal the opportunity and potential methods to select and efficiently plan and manage resilient forest ecosystems under uncertain climate change, by modelling the changes in amounts of delivery of ecosystem services using indicators, under different climatic responses to elevated Green House Gas emissions (Brown et al. 2011). When combined with the new forest management typology of FMA (Duncker et al. 2012; Jactel et al. 2012; Mason and Perks 2011) we can better define trajectories of change towards different forest ecosystem states. Forest planners may then assess the simulated effectiveness of FMA combinations as climate change adaptation measures to maintain resilient forests, capable of continuing to deliver a range of important ecosystem services into the future. 
This study evaluates the six UK NEA scenarios into forest policy options that could lead to the application of four forest management trajectories within an uncertain future changing climate to assess the various impacts those trajectories have upon future ecosystem service provision from two forests in Wales, UK. Uniquely, the dynamic simulation approach of this study can maintain a rate of transformation from the current suite of tree species, or management systems, to future alternative forest conditions, which is consistent with forestry practice constraints. The results from the simulation, through a period of transformation, show how each of the four trajectories can be trialled as climate change adaptation methods. This is achieved through the use of indicators of delivery of ecosystem goods and services, to assess and understand the future resilience of different adaptation techniques to climate change.

\section{Methods}

The study involved four main strands of work: downscaling of the UK NEA scenarios through forest management trajectories; assembly and interpolation of climate data; simulation of decadal forest management schedules; and calculation of ecosystem goods and service indicators for each climate projection. Additional information describing detail of these methods is available as online supplementary material (in Appendices A and B).

\section{Study sites}

The study focuses on two contrasting plantation forests in Wales: Clocaenog and Gwydyr. Both forests are certified according to the UK Woodland Assurance Scheme, overseen by the Forestry Stewardship Council, showing each is sustainably managed to deliver a range of benefits. Compared to Clocaenog forest, the main areas of Gwydyr forest have a lower elevation range, higher moisture deficit range, are more sheltered (low DAMS exposure score-'Detailed Aspect Method of Scoring wind exposure'), and contain a range of soils developed from a slightly more fertile lithology. Although featuring largely non-native species, Gwydyr forest $\left(56^{\circ} 6^{\prime} \mathrm{N}-3^{\circ} 1^{\prime} \mathrm{W}\right)$ lies within Snowdonia National Park and is thus regarded as an important forest area for tourism, providing high landscape and recreation value from a wide range of coniferous and broadleaved species. Clocaenog forest $\left(53^{\circ} 4^{\prime} \mathrm{N}-3^{\circ} 29^{\prime} \mathrm{W}\right)$ provides greater timber production potential and holds a larger proportion of spruce and pine than Gwydyr. In both forests, forest design planning in the last decade has focused on low-impact silviculture systems, particularly continuous cover forestry systems. In the UK, forest design plans are the method by which the public forest estate management is described and agreed with stakeholders in the forest planning process. Design plans describe spatially the location, area, and tree species choice used in plantation forests.

Downscaling the UK NEA scenarios through adaptive forest management trajectories

The six scenarios developed by the UK NEA (HainesYoung et al. 2011) were considered in terms of their likely effect on forest policy as well as on the range of management trajectories and FMAs to be applied on the ground. This exercise was undertaken in a two stage process. First, a panel of eight experts in forest policy 'stresstested' policies and practices against a series of changing socio-economic and climate change drivers within the UK NEA scenarios. This process enabled current decision strategies to be 'future-proofed' to avoid 'lock-in' to unsustainable policies or management practices. Next, six researchers with experience in forest management and the development of the scenarios, including those developed for the UK NEA, determined the linkages between the policy responses and the forest management systems likely to be used to implement that policy.

Policy definitions were linked to one of four different adaptation management trajectories: 'business as usual' replacing the same species and FMA type following felling, 'tree species diversity' selecting better suited species into the future, 'short-rotation forestry' replacing felled sub-compartments with short rotations, and 'low-impact silviculture systems' replacing felled sub-compartments with a continuous cover shelterwood. Each of these was defined by a small suite of possible FMAs (Mason and Perks 2011) that could deliver the required policy objective in practical terms. The FMA classification scheme (Duncker et al. 2012) assumes that as forest management intensity increases so does the economic gain, but at the cost of social and ecological benefits. The downscaling of the UK NEA scenarios through forest policy, into forest planning and finally to silviculture systems, leads to the FMAs (see Tables 1A-supplementary information, Appendix A), and a brief description of the UK NEA scenarios (Appendix B-supplementary information).

\section{Climate change projections}

The set of climate projections, known as the 11-member Regional Climate Models (11-RCM), were selected and interpolated to a resolution suited to catchment-based, landscape scale studies. These data comprise eleven model runs in which key parameters were perturbed to reflect uncertainty in the physical parameterisation of the climate 
model. Hadley RCM was used in UKCP09 to produce eleven runs of regional climate projections at the medium emissions scenario (A1B) IPCC SRES (IPCC 2000) on a daily basis. These data contain all the required variables to calculate the two main climatic inputs to the Ecological Site Classification (ESC) model (Pyatt et al. 2001) accumulated temperature and moisture deficit—and were supplied as daily values at $25-\mathrm{km}$ resolution. Daily simulations of mean temperature, precipitation, and potential evapotranspiration were accessed from the British Atmospheric Data Centre, for the period 1950-2099. Potential evapotranspiration for short grass was used as a relative index of the evaporative demand, allowing a spatial and temporal assessment of evaporation that is independent of the variation in the land cover surface. The 11-RCM variants can be interpreted as being within the boundaries of the A1B IPCC SRES climate change scenario, with an equal realisation probability. Historical model bias in each variant was removed by applying a relative adjustment, calculated as the difference between the simulated and observed baseline data over a 30-year climatic baseline period (1961-1990). The daily simulations were processed into monthly values, and these were used to calculate annual climatic moisture deficit and accumulated temperature for each of the 11-RCM variants from 1950 to 2099.

An increase in the spatial resolution of the $25-\mathrm{km}$ gridded data was required to represent the variation in projected values based on a number of known factors: latitude, longitude, and altitude. A relationship between the $25-\mathrm{km}$ data for accumulated temperature and moisture deficit was sought which could predict the output with a sufficient statistical accuracy, and which could be applied convincingly to simulate distributions over smaller areas. Matched 25-km grids were created for mean altitude and centroid latitude and longitude as inputs into a multiple linear regression model to predict the accumulated temperature or moisture deficit value.

Dynamically coupled forest management simulation to calculate goods and service indicators

Our approach was to simulate four alternate adaptation strategies in two plantation forests in Wales, through the forest planning and management cycle. This used a dynamic coupling of five UK forestry models, linked to six socio-economic futures of the UK NEA, and assessed using nine ecosystem services indicators through a changing climate of 11-RCM variants (Fig. 1), and no-climate change. Figure 1 shows the schema of the simulation, emphasising the relationships between the biophysical and climatic data, with the socio-economic scenarios, and the use of FMAs to describe different adaptation trajectories. Figure 1A (supplementary information, Appendix A) provides the detail of how models were coupled and applied to simulate planning, management, thinning, and harvesting schedules, and the provision of a range of forest ecosystem service indicators (see Table 2A-supplementary information, Appendix A). Simulation initialisation was achieved using a current digital spatial inventory of sub-compartments (each comprised of one or a few forest stands), called the sub-compartment database. This database contained information about the species composition, age, and their management for each of the two forests.

Each sub-compartment was attributed accumulated temperature and moisture deficit values for each decade based on the value at its centre. In addition, pre-calculated values of the DAMS wind exposure score, which is comprised of both wind climate and topographic factors (Gardiner et al. 2000), and Continentality (Conrad 1946) were located at the sub-compartment centre. A 1:10,000 scale digital soil map provided high-resolution information of the soil quality values for the dominant soil type in each sub-compartment: soil moisture regime (soil wetness) and soil nutrient regime (soil fertility) (Wilson et al. 2005). The 12 accumulated temperature and moisture deficit layers from the 11-RCM variants, plus a twelfth layer representing the baseline climate, provided site type input data for the UK forest classification model Ecological Site Classification (ESC) (Pyatt et al. 2001) to predict the yield and suitability of each tree species described in the sub-compartment database using the climate projections.

The predicted yield class from ESC was used in the UK Forest Yield (Matthews 2008) model to predict stand development (tree height, diameter, volume and stocking density) over a rotation. Stand variables from Forest Yield (Matthews 2008) became inputs to the UK wind risk model ForestGALES (Gardiner and Quine 2000) to calculate a wind damage risk score. ForestGALES is able to calculate the level of risk to forests over a whole rotation and to include the acclimation of trees to the changed wind exposure following thinning. Assortment modelsASORT - were used to determine the volume of saw-logs and small roundwood. BSORT (McKay et al. 2003) is a model to partition biomass and was used to estimate carbon stocks. Rotation lengths were developed from information in Forest Yield (Edwards and Christie 1981) in conjunction with stand management derived from the FMA assigned to the sub-compartment. The recreation indicator (Edwards et al. 2011) is a direct function of stand age, species composition, and the type of forest management. The biodiversity indicator was also related to stand age. The occurrence of various forest operations throughout the life of the stand (establishment, thinning/re-spacing, felling) was used to provide an indicator of forest employment potential based upon the number of interventions per decade. Following harvesting of a sub-compartment, the 


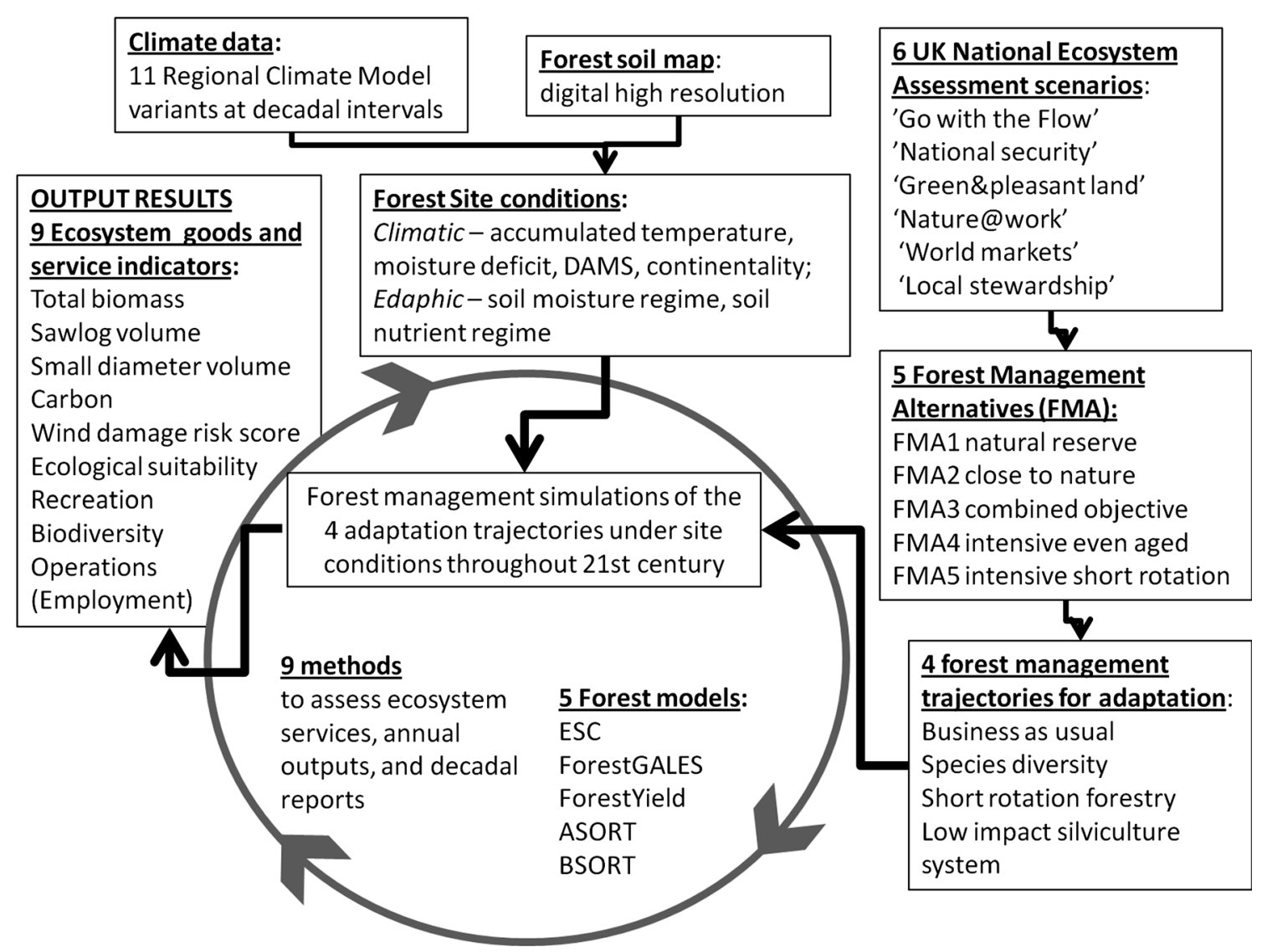

Fig. 1 Schema of five dynamically coupled British forest models (Ecological Site Classification, ForestGALES, Forest Yield, ASORT, and BSORT) to simulate plantation forest planning, management, thinning, and felling in Wales, with outputs transformed to a set of

decision to change the species (according to the climate in the subsequent rotation) or the FMA was made using a set of rules (Table 3A-supplementary material, Appendix A) based on published guidance by the Forestry Commission appropriate to the simulated management trajectory. More detailed information of the indicator methods and FMA descriptions are provided in Appendix B (supplementary material).

For this simulation study, we assumed that forest management was applied at the sub-compartment level (varying in size from 5 to $20 \mathrm{ha}$ ), and this is often the case in practice. However, occasionally sub-compartments contain unmapped components representing separate forest stands, and although could be managed differently, we were not able to run the simulation at a component level. The lowimpact silviculture systems' definition includes small patch felling and continuous cover forestry management, and so we have made the assumption that this is equivalent to FMA 2-'close to nature' forestry. Our simulation of a low-impact silviculture system assumes a transformation process from a single species-single-aged stand, to a nine indicator variables (carbon stocks, wind risk damage score, recreation, biodiversity, timber production, biomass production, small-wood production, employment (interventions), and tree species suitability)

single species-double-aged stand, where the two components form a uniform shelterwood system within the selected sub-compartment. Under this system, the ForestYield model can be used separately for each component. Other FMAs include: FMA1 - 'natural reserve', FMA3'mixed objective', FMA 4-'intensive even aged', FMA 5-'intensive short rotation'. It should also be noted that three of the management trajectories (business as usual, low-impact silviculture system, and short-rotation forestry) assumed the use of the same species in successive rotations in a sub-compartment. At the time of restocking, we simulated a change to a more suitable tree species (matched to soil and climatic conditions - the site type) only for the tree species diversity trajectory. None of the management trajectories assume any changes to the forest area.

\section{Results}

Results of the study are organised in three sections: first an analysis to interpolate to higher resolution the eleven 
climate change variants; second a description of the linkages from the six UK NEA scenarios through four forest management trajectories to each of five FMAs; third a presentation of changes in ecosystem service indicators for each of the forest management trajectories in turn. Additional information describing detail of these results is available in Appendix C (supplementary material).

Interpolating climate data

The predictive power of the regression technique for interpolating climate data to a higher resolution was very good for accumulated temperature $\left(\mathrm{r}^{2}\right.$ values $\left.\sim 0.9\right)$ and good for moisture deficit $\left(r^{2}\right.$ values $\left.\sim 0.6\right)$. Residuals were analysed and mapped to understand spatial variation and check for bias and error. For each variable and each of the 11-RCM data sets, the linear regression was used to create $250-\mathrm{m}$ gridded data for the UK by applying the equation to 250-m data sets of mean altitude and centroid latitude and longitude (see Appendix C, section $\mathrm{C} 1$, supplementary material).

The 250-m resolution 11-RCM accumulated temperature and moisture deficit data were used in the ESC model to assess the suitability of tree species through time and through a changing climate. To achieve this, the ESC accumulated temperature and moisture deficit values for each climate projection variant were calibrated by adjusting values so that the means for the 30-year climatic baseline period (1961-1990) matched mean values from climatic baseline observations. Calibration was performed using a linear regression analysis between 1000 randomly sampled paired points from both 250 -m UK grids, with a very high $r^{2}$ value $(\sim 0.975)$. Residuals were mapped to look for bias and error. This produced a final set of 216 climate data sets representing the baseline (1961-1990) and each mean 30-year decadal period from the 2010s to 2080s for each 11-RCM variant for both the accumulated temperature and moisture deficit variables, including a nochange scenario.

Simulation of the management trajectories

for Clocaenog and Gwydyr forests

The models in the simulation report results on a decadal basis, but the simulation is executed each year, aggregated for each decade, and presented on a per hectare basis to allow comparison between the two study sites, using units shown in Table 2A (supplementary material, Appendix A). In studying indicator results and in comparing the two study forests, it is important to keep in mind the aggregate age structure of sub-compartments, as well as FMA proportions, which differ for each forest (Tables 4A; Figure $2 \mathrm{~A}$-supplementary material, Appendix A). The forest age structure has a direct effect on the temporal distribution of goods and services, and this causes indicators: production, biomass, small wood, and carbon stocks, to show a steep dip in out-turn between 2040s and 2060s before recovering towards the end of the century, as does the wind damage risk score and operations to a lesser extent. The full results of the simulation (supplementary material, Appendix C, Section C2) show indicator values for shortrotation forestry, species diversity, and low-impact silviculture systems relative to the business as usual trajectory (with business as usual in absolute values). The relative values remove the effect of the sub-compartment age structure, and this helps show changes in the goods and services indicators.

Tree species suitability indicator

The current forests of Clocaenog and Gwydyr contain Sitka spruce (Picea sitchensis) as the dominant species, which grows well in mild and moist climatic conditions. Given the warmer climate simulated by all the variants with a much drier climate simulated for five variants, there was a decline in the forest suitability index with no-change in tree species. For some variants (e.g. 3Q3), the impact was predicted severe for all species with a low-tolerance to high-moisture deficits. Many conifer species exhibit stem cracks when the moisture deficits reach levels predicted in the variants studied. Using ESC, it was possible to test for a suitable replacement species for each variant in the simulation, when a site was restocked using the species diversity trajectory. Table 4A (online supplementary materialAppendix A) shows species changes for each of the climate variants. Spruce proportions decreased, while pines, broadleaves, and other conifer species not yet common in UK forestry (e.g. coast redwood) increased. For Clocaenog the range of site types was not as great as at Gwydyr, so the availability of sites suited to fir and broadleaves was reduced, compared to Gwydyr, where more sites were transformed to pines.

Welsh forest policy favours increasing species diversity, and particularly the choice of species that are well suited to site conditions (soils and climate). The species diversity trajectory allowed ESC to choose the most suitable species from a candidate list, to replace a sub-compartment at felling. The impact of this trajectory compared to business as usual on the mean area weighted suitability scores was to maintain the forest area with species suited to site conditions for the whole-rotation length. Take for example the climate variant 3Q3 (Fig. 2) which showed the greatest decline in suitability in business as usual. By 2080, 3Q3 would render much of the forest under business as usual as unsuitable for forest production, as the suitability score approached 0.2. The species diversity trajectory was able to 

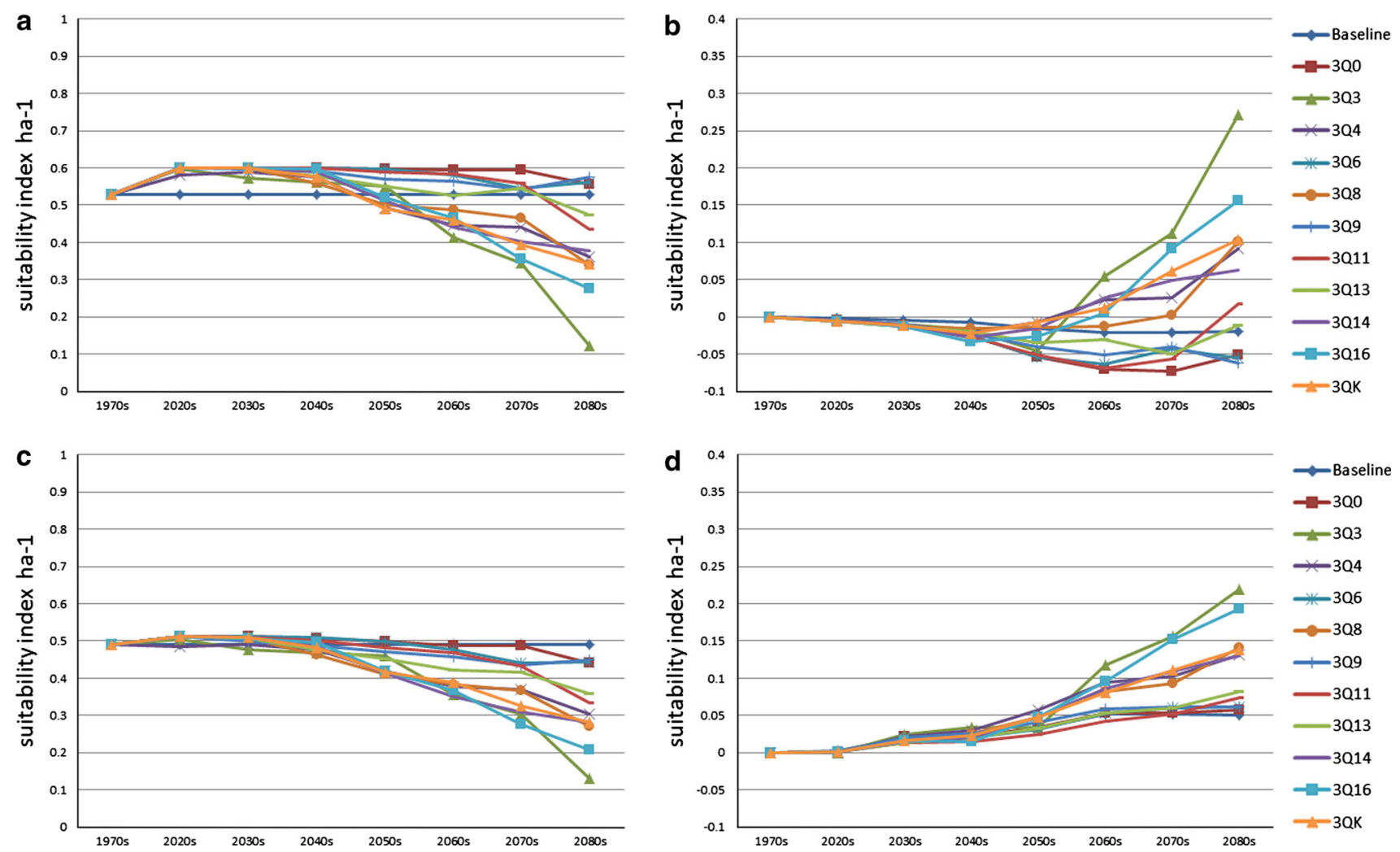

Fig. 2 Differences in the mean suitability index of a, b Clocaenog forest and c, d Gwydyr forest, for the business as usual (BAU) management trajectory (a, c), and the species diversity (DIV) trajectory $(\mathbf{b}, \mathbf{d})$. Suitability scores show the suitability of forest sites

replace the business as usual species with a more droughttolerant alternative, and for $3 \mathrm{Q} 3$ at Gwydyr under species diversity, this resulted in an increase in suitability of 0.3 over business as usual bringing the species suitability for the forest as a whole back up to 0.5 (suitable for timber production), and 0.35 at Clocaenog (marginal for timber production).

Diversification of species across all climate variants indicated an increased opportunity for pines (Scots pinePinus sylvestris, Macedonian pine-Pinus peuce), firs (noble fir-Abies procera; grand fir-Abies grandis; Douglas fir-Pseudotsuga menziesii), and other conifers (usually coast redwood-Sequoia sempervirens and western red cedar-Thuja plicata). The algorithm selected species according to ecological suitability and volume production but did not consider the mechanical properties of the timber.

Carbon stocks, timber production, and biomass indicators

The Clocaenog carbon indicator increase was less pronounced as only $6 \%$ of FMAs were transformed to a lowimpact silviculture system. The extent of the transformation for production forestry and vary between 0 and 1, where: $0-0.4$ is unsuitable, $0.4-0.5$ is marginal, $0.5-0.75$ is suitable, and $0.75-1$ is very suitable. Note $\mathbf{b}, \mathbf{d}$ are shown as relative differences from $\mathbf{a}, \mathbf{c}$

at Gwydyr was also seen in the steep rise of wind damage risk scores between 2040s and 2070s, as stands with a DAMS of less than or equal to 14 were heavily thinned to promote regeneration and were therefore exposed suddenly to potential wind damage for several years before canopy gaps closed.

The business as usual trajectory shows the effect of the existing age structure of each forest, which produced a peak in timber production in the 2050s at Clocaenog and double peaks from Gwydyr in the 2040s and 2060s.

Biomass peaked in the decade prior to the increase in felling-2030s at Clocaenog and 2020s at Gwydyr. The business as usual trajectory at Clocaenog, and to a lesser extent at Gwydyr, showed that the early peaks were higher for timber production, biomass production, and carbon stocks (prior to felling) for all climate projection variants compared to the baseline simulation. Conversely, smallwood production $(<0.17$-m-diameter class $)$ projections reduced for all climate variants compared to the baseline climate simulation. However, later in the century, for each of timber production, biomass production, and carbon, the projected range of values from different climate variants increased, and indeed some remained above the baseline 

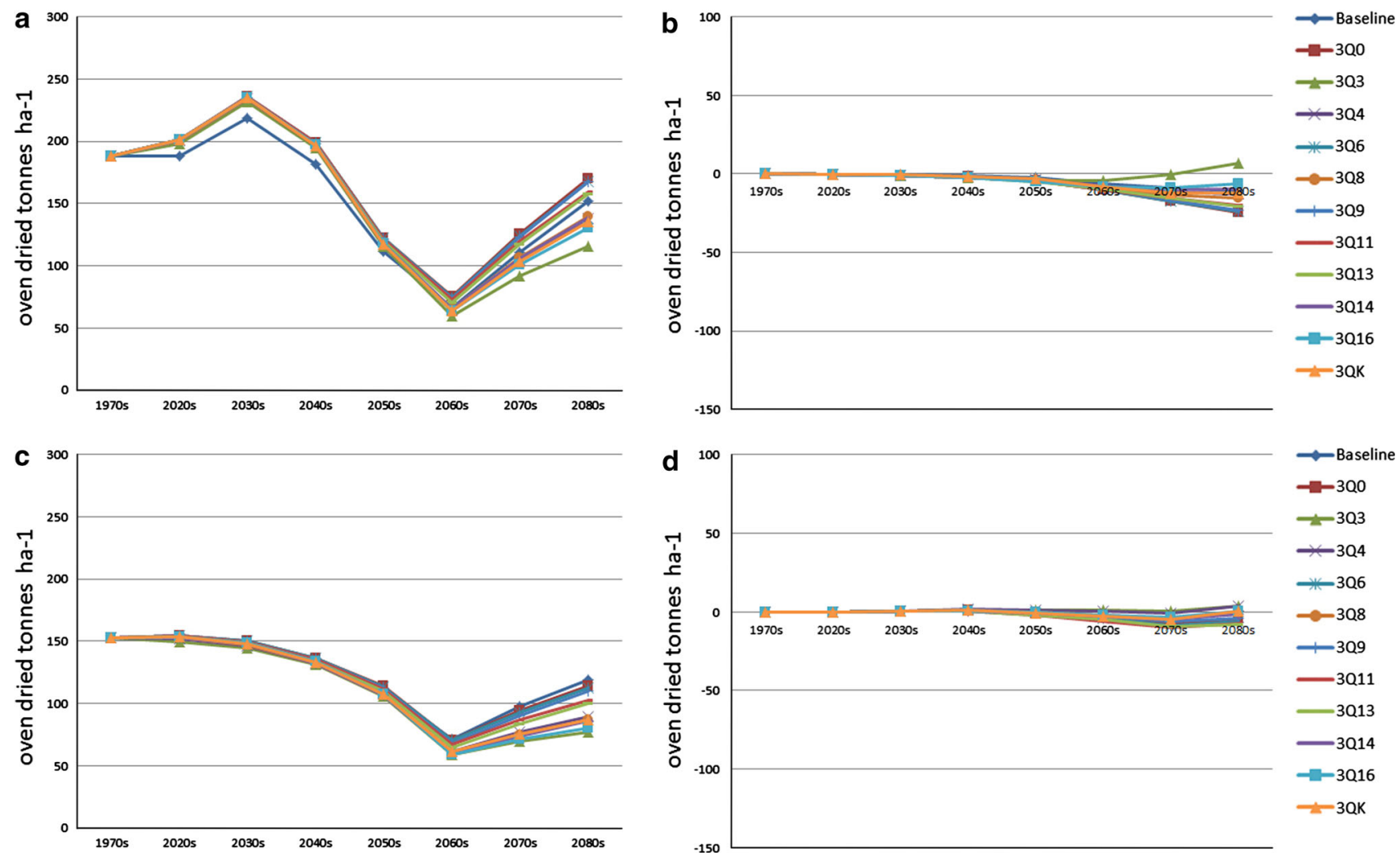

Fig. 3 Differences in the total biomass production (oven-dried tonnes $\mathrm{ha}^{-1}$ ) for two forests $\mathbf{a}, \mathbf{b}$ Clocaenog forest and $\mathbf{c}, \mathbf{d}$ Gwydyr forest, for the business as usual (BAU) management trajectory $(\mathbf{a}, \mathbf{c})$,

and the species diversity (DIV) trajectory (b, d). Note $\mathbf{b}, \mathbf{d}$ are shown as relative differences from $\mathbf{a}, \mathbf{c}$

climate projection (3Q0, 3Q6, 3Q11, and 3Q13), while others (3Q8,3Q14, 3QK, 3Q16, and 3Q3) indicated lower forest production than was simulated by the models for noclimate change. The timber production, biomass, and carbon projections for the species diversity, and low-impact silviculture systems trajectories, maintained similar or slightly lower levels to the business as usual. The main effect at Clocaenog was that by the end of the century (Fig. 3), compared to business as usual, species diversity reduced the uncertainty of biomass production but at a maximum trade-off loss of $70 \mathrm{t} \mathrm{ha}^{-1}$ to reduce an uncertain biomass production range of $150 \mathrm{tha}^{-1}$ from the forest under a business as usual trajectory. At Gwydyr there was no trade-off in biomass under a species diversity trajectory and the range of uncertainty in biomass production was also removed. For each of these indicators, the shortrotation forestry trajectory showed declining levels from mid-century compared to business as usual. This was because short-rotation forestry rotations led to the felling of trees at age 25 , whereas the peak in maximum mean annual increment often occurs beyond the age of 50 (i.e. two 25-year rotations produce less extractable material than one 50-year rotation). However, short-rotation forestry would afford many opportunities to adapt species to a

changing climate. The low-impact silviculture systems trajectory for Gwydyr showed a gradual increase in biomass carbon stocks, but a reduction in timber production, in response to a $13 \%$ increase in sub-compartments under transformation and remaining un-felled as the FMA4 (intensive even age) sub-compartments were re-allocated to FMA2 (close to nature) and thinned to half the number of stems at age 50. At Clocaenog, the relatively small area available for transformation to low-impact silviculture systems exerted a smaller increase in carbon stocks and biomass with a smaller reduction in timber production through the century.

Wind risk indicator

By the 2040s, wind damage risk score increased by a small amount for the business as usual trajectory in both forests and then declined as more mature sub-compartments were replaced. Compared to business as usual, the species diversity trajectory showed the wind damage risk score to increase very marginally from mid-century as the alternative drought-tolerant species selected in place of Sitka spruce would grow faster in the warmer climate and would therefore become more susceptible to wind damage 
compared to slower growth in the business as usual trajectory. Similarly, wind damage risk score for the lowimpact silviculture systems trajectory increased and peaked in mid-century at Gwydyr with $13 \%$ of the forest transformed to low-impact silviculture systems, whereas at Clocaenog only $6 \%$ could be transformed to low-impact silviculture systems, and this would not have a big effect on the wind damage risk score for the whole forest.

\section{Biodiversity and recreation indicators}

Biodiversity and recreation indicators have some similarities as they are based largely on stand age and FMA. For both forests, the biodiversity and recreation indicators remained more or less constant through the century for the business as usual trajectory. Since stand age is a factor of both, the shortrotation forestry trajectory showed a gradual decline through the century as the proportion of stands under the 25-year rotation length increased. The species diversity trajectory had little effect on biodiversity or recreation as this trajectory is concerned only with productive species selection, and not FMA. However, there was a gradual increase in the biodiversity indicator in the low-impact silviculture systems trajectory at Gwydyr, as up to $13 \%$ of the forest was under transformation to a shelterwood system.

\section{Operations (employment) indicator}

The operations indicator provides an index of employment, through the number of interventions required per decade. At Clocaenog this remained constant for all trajectories throughout the simulation at a level just below one per decade. Since the DAMS score was higher at Clocaenog and thinning less widely practised, transformation from 'intensive even age' (with mainly no-thinning) to FMA5 with no-thinning had little impact on operations frequency. At Gwydyr the operations indicator for the business as usual trajectory maintained a value just below 2 per decade, and this declined to slightly under 1 per decade by the 2080s for the short-rotation forestry trajectory, as thinning stopped in sub-compartments transformed from FMA4 (thinning every 5 years) to FMA5 (with no-thinning).

\section{Discussion}

The range of ecosystem goods and services indicators assessed in the study were intended to demonstrate some of the trade-offs and synergies exposed in land-use change. Many of these ecosystem services are familiar in the forestry literature, e.g. biodiversity, carbon (Gamfeldt et al. 2013; Onaindia et al. 2013), and production (Rist and Moen 2013). The novelty of our approach developed indicators well suited to the spatial forest data, and which could be used to demonstrate both spatial and temporal change. We used the amount of ecosystem services provided in the baseline climate as a standard to assess how adaptation measures were able to maintain baseline levels of ecosystem services delivery into an uncertain climate change future. Our choice of indicators for the continued sustainable forest management of plantation forests, continue to show the importance, rather than dominance, of forest productivity. Without productive forests, which help maintain the forestry sector, it would be difficult deliver other services. Indeed our simulation demonstrated this in the 'World Markets' scenario.

\section{Climate change projections}

Exploration of impacts of climate projections inevitably requires some judgement in selecting which climate realisations to work with. Ten years ago there was no choice, as few projections were available. Recently, more use has been made of RCM (Bell et al. 2007; Blenkinsop and Fowler 2007; Yousefpour et al. 2013), and there is some evidence that RCM projections are better suited to regions of complex topography (Kueppers et al. 2005). In addition, the interpolation of accumulated temperature and moisture deficit of $25-\mathrm{km}$ cells to high resolution of $250 \mathrm{~m}$ using data for the whole of the UK reduced the elevation bias in the results caused by the mountainous area adjacent to Gwydyr forest.

\section{Species diversity implications}

Simulating species diversity maintained suitability scores from the forest to a level that would just support production forestry in the 2080s, at a marginal level in Clocaenog and a suitable level at Gwydyr. The range of variants helps forest planners to explore the range in climate space, to assess possible futures and risks before making a decision. This is a form of climate model sensitivity testing that helps planners judge the worst- and best-case scenarios, and the potential exposure to risk of decisions. Species diversity reduced the uncertainty of timber production, biomass, and carbon stock levels through the century, although at a cost of reduced production, but this might be an important consideration for forest districts needing to commit to achievable production targets. The species diversity trajectory also improved recreation mainly through the substantial selection of broadleaved species. Although public perception suggests broadleaved stands have a similar recreation potential compared to conifers (Edwards et al. 2012), the introduction of broadleaved stands within conifer forests highly influences forest structure, and structural diversity is scored more highly. 
Low-impact silviculture implications

Our simulation showed that in each forest, compared to business as usual clear-fell systems, there were biodiversity gains for low-impact silviculture systems at a stand level by transforming sub-compartments to FMA2 (close to nature). The age structure within Gwydyr enabled faster transformation within the study period (56 vs. $7 \%$ in Clocaenog) and resulted in a $40 \%$ gain in the biodiversity index compared to business as usual management. The biodiversity indicator relates older stands managed using low-impact silviculture systems to increases in deadwood and light penetration (Humphrey et al. 2002, 2004) to stimulate regeneration and a field layer. The related recreation indicator (Edwards et al. 2011) shows people respond positively, and perhaps sympathetically, to lowimpact silviculture systems by scoring highly stands which contain (some) bigger and older trees and with greater structural diversity (Edwards et al. 2012). Low-impact silviculture systems improved the recreation indicator by $50 \%$ at Gwydyr forest, compared to business as usual, because of its greater potential for transformation. Turning to timber production, small-wood production, biomass, and carbon stocks, the low-impact silviculture systems trajectory performed well compared to business as usual, with improved biomass and carbon stocks at Gwydyr, neutral effects at Clocaenog, and no adverse impact on production in either forest. A further benefit from low-impact silviculture systems was that larger trees increased the output of saw-log material over the less valuable small-diameter wood. The study did not consider the use of under-planted alternative species to mitigate against future conditions in low-impact silviculture systems sub-compartments. For example, this might involve patch clear-felling spruce and rather than relying upon natural regeneration, actively planting a new under-storey with a species likely to be suitable now and in the future.

\section{Timber quality issues}

In some circumstances, a switch in species could result in timber quality issues. Pine species can generally yield higher strength grades (based upon density and modulus of elasticity) than Sitka spruce, as can Douglas fir (Lavers 2002). However, where simulations increased the fir component, this was often based on grand fir, which despite yielding high volumes of timber, produces structurally inferior material that cannot enter high-value markets. In practice, it is likely that Macedonian pine, Douglas fir, western red cedar or coast redwood would be planted dependant on site characteristics. Despite a lower yield potential than grand fir, the alternative species would better satisfy an objective to produce construction grade timber, and as a consequence the volume out-turn indicators would be a little lower than predicted in the simulation.

UK NEA scenario impacts on forest management and ecosystem services

'World Markets' assumes extreme uneconomic conditions for the forestry sector in the UK. For this scenario, we indicated a transformation to short-rotation forestry, leading to reduced recreation, declining biodiversity, fewer operations, and less employment. Although biomass and carbon stock declines are indicated, carbon lifecycle analyses indicate that fossil-fuel substitution benefits of biomass from short-rotation forestry far outweigh the mitigation value (Morison et al. 2012), as long as substitution occurs. 'Go with the Flow' and 'National Security' indicate a non-adaptation stance, persisting with a business as usual trajectory. The simulation indicates an increase in small-wood production through the mid-century, but this supply would be available with no effective market, and its value would reduce to fire wood supply or abandonment. For 'National Security', there would be a large demand for woodland expansion that could satisfy short-rotation forestry and pulp products while existing stands mature to provide saw-logs and higher quality products. This would additionally fill the simulated gap in biomass and timber production through the mid-century period. A 'National Security' scenario would favour species diversity, particularly a transformation to high yielding conifers, and so the species diversity trajectory may apply here to a small extent. The 'Green and pleasant land' and 'Nature@work' scenarios focus more on species diversity and for the latter on low-impact silviculture systems. The results appear to show different outcomes for the two forests for low-impact silviculture systems and species diversity. The forests differ in terms of the range of sites available. Clocaenog has relatively little potential for low-impact silviculture systems and limited selection of species for species diversity, compared with Gwydyr. This reduces the potential to choose suitable species for the available sites transformed, and only a limited number of potential sites are available at Clocaenog compared to Gwydyr. Consequently, there is a slight reduction in biomass with climate projection variants, while at Gwydyr the biomass increases for all climate projections compared to the baseline or to no-climate change. The opportunities for adapting forests to climate change are improved in 'Green and pleasant land' and particularly in the 'Nature@work' scenario, in which the latter is more focussed on ecosystem service delivery, allowing greater flexibility in species choice than the former, with a biodiversity focus. In Wales a 'Local stewardship' scenario fits well with the current forest policy, in which both low-impact silviculture systems and species 
diversity are actively promoted in a Natural Resources policy to deliver ecosystem services. Our simulation suggests that low-impact silviculture systems and species diversity in woodlands will continue to deliver the ecosystem services from both forests.

Combining species diversity with low-impact silviculture

Rasche et al. (2013) reported improvements in productivity and biomass in stands with greater 'mixed' species diversity. They also reported that the low-impact silviculture systems management (plentering or single stem selection) did not improve productivity and that other measures would need to be taken such as the introduction of more drought-tolerant species. Our study suggests reductions in the loss of productivity due to dry future climatic conditions, through a selection of species better suited to changing site conditions. Steenberg et al. (2011) reported that a combined adaptation strategy that created greater structural diversity, and which promoted increased drought-tolerant species, was effective in preventing loss of productivity, and maintaining timber supply. Our study suggests similar results would occur, if both the species diversity and low-impact silviculture systems management trajectories were combined.

By combining low-impact silviculture systems with a species diversity trajectory, the forest is more likely to remain productive as defined by the suitability scores for the most extreme dry climate variant $3 \mathrm{Q} 3$, and the very small variations in the timber production indicator for species diversity compared to business as usual at both forests. Combining these two approaches as the opportunity arises is similar in concept to active adaptation (Bolte et al. 2009), but differs somewhat from the approach of focusing management on specific outcomes (Yousefpour et al. 2013) by mixing both FMA transformation and species selection systems to different end points. Instead, we separated the FMA transformation process to low-impact silviculture systems or short-rotation forestry and the species selection processes to compare extreme but practically feasible changes based on site conditions. Our species diversity adaptation trajectory was 'forward looking' (Yousefpour et al. 2013) since it considers suitability under the climate projections throughout the rotation length. Yousefpour et al. (2013) considered this point key to allowing forest planners and managers to update their beliefs with access to actual climate developments as the century progressed. Our simulation provides an early glimpse of possibilities through the century, and because we can simulate adaptation progression at a realistic rate given limited time and machinery resources, there will be realistic review points where new adaptation pathways can be defined if plans do not proceed as intended.
Forest policy implications

Recent forest policy in Wales (FCW 2009) has been influenced by the need to diversify plantation forests, to adapt to climate change, to increase and maintain forest biodiversity, and to improve visual amenity. This is being progressed where site conditions allow, mainly by the transformation of even aged plantations to low-impact silviculture systems (Mason and Perks 2011), and now with practice guidance (Carrick 2010). Although two of the three forest management trajectories simulated in our study are familiar to forest policy and practice teams, the climate change adaptation and ecosystem service delivery consequences of transforming forests from patch clear-fell systems to more species diverse forest using low-impact silviculture systems were unclear. Rist and Moen (2013) clarified differences between the ecosystem approach (sustainable forest management) and an adaptive management approach, showing that in adaptive management there is often a need to make decisions to reduce uncertainty and improve short-term efficiency for specified objectives. They described how adaptive management may lead to an erosion of the ability of a forest ecosystem to withstand other unknown disturbances. Resilience thinking management, they argued, accepts sub-optimal short-term outcomes to maintain longer-term options into the future. Our study demonstrates this, since climate change adaptation trajectories without review and adjustments, or without an assessment of alternative trajectories, and particularly without any consideration of uncertainty, may lead to unexpected reductions in the range and amount of ecosystem services. This study should therefore signal to Welsh Government policy makers and more widely to forest policy makers in the other devolved administrations of the UK two opportunities: firstly, the climate change adaptation potential of transforming plantations using lowimpact silviculture systems with more diverse species suited to site conditions, and secondly, the potential of simulation approaches to assessing future ecosystem services delivery, and the inherent uncertainty, to assess the efficacy of land-use planning projects.

\section{Conclusions}

The dynamic simulation was extremely successful at identifying areas of strengths and weaknesses of forest management intervention to the resilience of forests, due to the projected uncertain effects of climate change. It is recommended that this type of simulation system should be used to test the resilience of all forest management designs, to help forest planners build resilience into forests. Doing so should make a big contribution to the ability of UK 
forests to consistently produce a valuable portfolio of ecosystem goods and services. Furthermore, we are sure that this type of simulation developed for forest land could be equally applied to catchment land-use situations. Compared to the broad UK national scale analysis of how forests and woodlands contribute ecosystem services in the six UK NEA scenarios, and which considered just one 'low-' and one 'high' climate change projection, our simulation of 11-RCM variants offers a more detailed view of the uncertainty of climate change, which better informs strategic planning and local decision-making. We conclude that in Wales, the current policy of promoting low-impact silviculture systems on suitable sites, and the promotion of a greater range of tree species used in silviculture should continue, to deliver a range of key ecosystem services from resilient forests. The range of UK NEA scenarios would have different impacts on woodland management and therefore on the delivery of ecosystem services and the adaptation capacity and resilience of plantation forests. It should be noted that the possibility of the widespread adoption of short-rotation forestry as a climate change mitigation option is likely to have an impact on biodiversity and recreation services.

Acknowledgments We gratefully acknowledge the financial support from the 7th Framework Programme (FP7) of the European Union (Project MOTIVE, ENV-CT-2009-226544) and Forestry Commission GB. We also wish to acknowledge access to the 11-member RCM simulated climate projections for the UK from the BADC portal. Finally, we are grateful to two reviewers and the guest editor for valuable comments.

Open Access This article is distributed under the terms of the Creative Commons Attribution License which permits any use, distribution, and reproduction in any medium, provided the original author(s) and the source are credited.

\section{References}

Bell VA, Kay AL, Jones RG, Moore RJ (2007) Use of a grid-based hydrological model and regional climate model outputs to assess changing flood risk. Int J Climatol 27:1657-1671

Benayas JMR, Newton AC, Diaz A, Bullock JM (2009) Enhancement of biodiversity and ecosystem services by ecological restoration: a meta-analysis. Science 325:1121-1124

Berkhout F, van den Hurk B, Bessembinder J, de Boer J, Bregman B, van Drunen M (2013) Framing climate uncertainty: socioeconomic and climate scenarios in vulnerability and adaptation assessments. Reg Environ Change. doi:10.1007/s10113-0130519-2

Blenkinsop S, Fowler HJ (2007) Changes in European drought characteristics projected by the PRUDENCE regional climate models. Int J Climatol 27:1595-1610

Bolte A et al (2009) Adaptive forest management in central Europe: climate change impacts, strategies and integrative concept. Scand J For Res 24:473-482

Broadmeadow M, Ray D, Samuel C (2005) Climate change and the future for broadleaved tree species in Britain. Forestry 78:145-167
Brown I, Poggio L, Gimona A, Castellazzi M (2011) Climate change, drought risk and land capability for agriculture: implications for land use in Scotland. Reg Environ Change 11:503-518

Carrick R (2010) A Guide for increasing tree species diversity in Wales. Forestry Commission Wales Policy Guidance. Forestry Commission Wales, Aberystwyth. http://www.forestry.gov.uk/ forestry/INFD-8BAFQ4

Conrad V (1946) Usual formulas of continentality and their limits of validity. Trans Am Geophys Union 27:663-664

Courbaud B, Kunstler G, Morin X, Cordonnier T (2010) What is the future of the ecosystem services of the Alpine forest against a backdrop of climate change. Revue de Geographie Alpine 98:4

Defra (2011) The natural choice: securing the value of nature (Cm 8082). The Stationery Office, London. ISBN 9780101808224

Duncker PS, Barreiro SM, Hengeveld GM, Lind T, Mason WL, Ambrozy S, Spiecker H (2012) Classification of forest management approaches: a new conceptual framework and its applicability to european forestry. Ecol Soc 17:51. doi:10.5751/ES05262-170451

Edwards PN, Christie JM (1981) Yield models for forest management. Forestry Commission Booklet 48. Forestry Commission, Edinburgh

Edwards DM, Jensen FS, Marzano M, Mason B, Pizzirani S, Schelhaas MJ (2011) A theoretical framework to assess the impacts of forest management on the recreational value of European forests. Ecol Ind 11:81-89

Edwards DM et al (2012) Public preference across Europe for different forest stand types as sites for recreation. Ecol Soc 17:27

FCW (2009) Woodlands for Wales-the Welsh Assembly Government's strategy for woodlands and trees. Forestry Commission Wales, Cardiff

Fürstenau C, Badeck FW, Lasch P, Lexer MJ, Lindner M, Mohr P, Suckow F (2007) Multiple-use forest management in consideration of climate change and the interests of stakeholder groups. Eur J For Res 126:225-239

Gamfeldt L et al (2013) Higher levels of multiple ecosystem services are found in forests with more tree species. Nat Commun 4:1340. doi: $10.1038 /$ ncomms 2328

Gardiner BA, Quine CP (2000) Management of forests to reduce the risk of abiotic damage - a review with particular reference to the effects of strong winds. For Ecol Manag 135:261-277

Gardiner BA, Peltola H, Kellomäki S (2000) Comparison of two models for predicting the critical wind speeds required to damage coniferous trees. Ecol Model 129:1-23

Haines-Young R, Paterson J, Potchin M, Wilson A, Kass G (2011) Chapter 25. The UKNEA scenarios: development of storylines and analysis of outcomes. In: The UK National Ecosystem Assessment Technical Report. UNEP-WCMC, Cambridge

Hanewinkel M, Cullmann DA, Schelhaas M-J, Nabuurs G-J, Zimmermann NE (2013) Climate change may cause severe loss in the economic value of European forest land nature. Clim Change 3:203-207

Humphrey JW, Davey S, Peace AJ, Ferris R, Harding K (2002) Lichens and bryophyte communities of planted and semi-natural forests in Britain: the influence of site type, stand structure and deadwood. Biol Conserv 107:165-180

Humphrey JW, Sippola A-L, Lempérière LG, Dodelin B, Alexander KNA, Butler JE (2004) Deadwood as an indicator of biodiversity in European forests: from theory to operational guidance. In: Marchetti M (ed) Monitoring and indicators of forest biodiversity in Europe-from ideas to operationality. European Forest Institute, Joensuu, pp 193-206

Hurteau MD, Bradford JB, Fulé PZ, Taylor AH, Martin KL (2013) Climate change, fire management, and ecological services in the southwestern US. For Ecol Manag. doi:10.1016/j.foreco.2013. 08.007 
IPCC (2000) In: Nakicenovic N, Swart R (eds) IPCC Special Report: Emission Scenarios: summary for policymakers. Cambridge University Press, Cambridge, UK

Jactel H et al (2012) A multicriteria risk analysis to evaluate impacts of forest management alternatives on forest health in Europe. Ecol Soc 17:52

Kueppers L, Snyder M, Sloan L, Zavaleta E, Fulfrost B (2005) Modeled regional climate change and California endemic oak ranges. Proc Natl Acad Sci USA 102:16281-16286

Lavers GM (2002) The strength properties of timber. Building Research Establishments Report Series 3. BRE

Lindner $M$ et al (2010) Climate change impacts, adaptive capacity, and vulnerability of European forest ecosystems. For Ecol Manag 259:698-709

Linnard W (2000) Welsh woods and forests. Gomer Press, Llandysul

Mason WL (2007) Changes in the management of British forests between 1945 and 2000 and possible future trends. Ibis 149:41-52

Mason B, Perks MP (2011) Sitka spruce (Picea sitchensis) forests in Atlantic Europe: changes in forest management and possible consequences for carbon sequestration. Scand J For Res 26:72-81

Matthews RW (2008) Forest yield, 4th edn. Forestry Commission, Edinburgh

McKay H, Hudson JB, Hudson RJ (2003) Woodfuel resource in Britain. Department of Trade and Industry Publication URN 03/1436, London

MCPFE (2006) The Pan-European understanding of the linkage between the ecosystem approach and sustainable forest management. Ministerial Conference on the Protection of Forests in Europe, Pan-European Biological and Landscape Diversity Strategy, Council of Europe, Geneva-Warsaw

MEA (2005) Millennium ecosystem assessment: ecosystems and human well-being - synthesis. Island Press, Washington

Millar CI, Stephenson NL, Stephens SL (2007) Climate change and forests of the future: managing in the face of uncertainty. Ecol Appl 17:2145-2151

Morison J et al (2012) Understanding the carbon and greenhouse gas balance of forests in Britain. Forestry Commission Research Report. Forestry Commission, Edinburgh

Onaindia M, de Manuel BF, Madariaga I, Rodríguez-Loinaz G (2013) Co-benefits and trade-offs between biodiversity, carbon storage and water flow regulation. For Ecol Manag 289:1-9

Petr M, Boerboom LGJ, Ray D, van-der Veen A (2014) An uncertainty assessment framework for forest planning adaptation to climate change. For Policy Econ 41:1-11
Pyatt DG, Ray D, Fletcher J (2001) An ecological site classification for forestry in Great Britain: Bulletin 124. Forestry Commission, Edinburgh

Quine C, Cahalan C, Hester A, Humphrey J, Kirby K, Moffat A, Valatin G (2011) Chapter 8: Woodlands. In: Watson RT, Albon SD (eds) UK National ecosystem assessment. UNEP-WCMC, Cambridge

Quine CP, Bailey SA, Watts K (2013) Sustainable forest management in a time of ecosystem services frameworks: common ground and consequences. J Appl Ecol. doi:10.1111/1365-2664.12068

Rasche L, Fahse L, Bugmann H (2013) Key factors affecting the future provision of tree-based forest ecosystem goods and services. Clim Change 118:579-593

Richards EG (2003) British forestry in the twentieth century, policy and achievements. Koninklijke Brill, Leiden

Rist L, Moen J (2013) Sustainability in forest management and a new role for resilience thinking. For Ecol Manag 310:416-427

Seidl R, Lexer MJ (2013) Forest management under climatic and social uncertainty: trade-offs between reducing climate change impacts and fostering adaptive capacity. J Environ Manag 114:461-469

Steenberg JWN, Duinker PN, Bush PG (2011) Exploring adaptation to climate change in the forests of central Nova Scotia, Canada. For Ecol Manag 262:2316-2327

Stein BA et al (2013) Preparing for and managing change: climate adaptation for biodiversity and ecosystems Frontiers. Ecol Environ 11:502-510

UKCP (2009) Online climate change projections report. http:// ukclimateprojections.defra.gov.uk/22633

UKNEA (2011) The national ecosystem assessment: synthesis of key findings. UNEP-WCMC, Cambridge

Wilson SM, Pyatt DG, Ray D, Malcolm DC, Connolly T (2005) Indices of soil nitrogen availability for an ecological site classification of British forests. For Ecol Manag 220:51-65

Yousefpour R, Jacobsen JB, Thorsen BJ, Meilby H, Hanewinkel M, Oehler K (2012) A review of decision-making approaches to handle uncertainty and risk in adaptive forest management under climate change. Ann For Sci 69:1-15

Yousefpour R et al (2013) Updating beliefs and combining evidence in adaptive forest management under climate change: a case study of Norway spruce (Picea abies L. Karst) in the Black Forest, Germany. J Environ Manag 122:56-64 